Bentham OPEN
CrossMark

\title{
Coats' Disease: Very Long-Term Outcome After Early Stage Conventional Treatment
}

\author{
Salvatore Perrone*, Alberto Rossetti, Patrick Sportiello, Pierfrancesco Mirabelli, Pierangela Cimatti \\ and Daniele Doro
}

Department of Ophthalmology, University Hospital of Padua, Padua, Italy

\begin{abstract}
:
Purpose:

To report on the outcome of conventional therapy in patients with Coats' disease.

Methods:

Retrospective analysis of the charts of thirteen patients with Coats' disease.

\section{Results:}

Mean age of 9 male (70\%) and 4 female (30\%) patients was 17.7 (range, 5-33) years; one female had bilateral disease. Eleven eyes with retinal telangiectasia and exudation were treated with argon laser photocoagulation alone or photocoagulation associated with cryotherapy; the mean follow up was 32.5 (range,17-41) years. In four eyes without foveal involvement (stage 2a) the mean presenting visual acuity (VA) remained at 0.8 or improved, whereas poor VA in seven stage $2 \mathrm{~b}$ eyes deteriorated minimally over time. In one and two of the three eyes with total retinal detachment, phthisis or neovascular glaucoma ensued.
\end{abstract}

\section{Conclusion:}

About three decades after conventional treatment of Coats' disease stage 2a, treated eyes maintained good VA, and stage $2 \mathrm{~b}$ eyes did not progress to advanced stages.

Keywords: Coats' disease, exudative retinopathy, neovascular glaucoma, retinal detachment, telangiectasia.

\section{INTRODUCTION}

Coats' disease, a distinct clinical entity characterized by idiopathic retinal telangiectasia and retinal exudation, is usually unilateral (about 90\%), and occurs predominantly in young males (about $75 \%$ of cases). Clinical findings are decreased visual acuity, strabismus and leukocoria [1, 2]. If left untreated, the disease can lead to total retinal detachment and neovascular glaucoma [3, 4]. According to Shields et al., Coats' disease can be staged as follows: retinal telangiectasia (stage 1), retinal telangiectasia plus extrafoveal and foveal exudation (stage 2a and 2b), subtotal and total exudative retinal detachment (stages $3 \mathrm{a}$ and $3 \mathrm{~b}$ ), retinal detachment plus secondary glaucoma (stage 4), and advanced end-stage (stage 5) [5]. The main goal of treatment should be to eliminate telangiectasia and abnormal leakage from the retinal vessels, thus facilitating the resolution of lipid exudation and preventing retinal detachment. In the early disease stages, this is best achieved with retinal laser photocoagulation or cryotherapy [1]. The estimated incidence of Coats' disease in the United Kingdom is 0.09 per 100,000 [6]. The rarity of the disease accounts for the scarcity of reports in the literature publishing studies on large patient series $[1,2,7]$.

\footnotetext{
* Address correspondence to this author at Dipartimento di Neuroscienze - Clinica Oculistica, Università di Padova, via Giustiniani 2, 35128, Padova, Italy; Tel: +390498212110, Fax: +390498755168; E-mail: salvatore.perrone@unipd.it
} 
The purpose of the present study was to evaluate the impact of conventional therapy on the very long-term functional and anatomical outcome in eyes with different stages of Coats' disease at presentation.

\section{MATERIALS AND METHODOLOGY}

A retrospective review was made of the charts of 13 consecutive Caucasian patients with Coats' disease treated at our ophthalmological department from 1972 to 1999 . The diagnosis was based on the presence of features including retinal telangiectasia, exudation, retinal detachment, and the absence of other vitreoretinal diseases, such as persistent fetal vasculature, retinal capillary hemangioma, retinopathy of prematurity, familial exudative retinopathy and retinoblastoma, which can mimic Coats' disease [1, 2]. The following information was searched for in each case: age at diagnosis, gender, disease stage, retinal sectors involved, sessions of argon laser retinal photocoagulation and cryotherapy and best-corrected visual acuity (BCVA) using the decimal scale at the first and last examination.

Each patient underwent a thorough ophthalmological examination that included indirect ophthalmoscopy, detailed fundus drawing and color fundus photographs. Fluorescein angiography, ultrasound B-scan and optical coherence tomography examinations were performed in some selected cases. The retinal areas considered to have telangiectasia and retinal exudation were: posterior pole and the nasal, upper, temporal and lower sectors. Eyes were staged according to the Coats' disease classification proposed by Shields et al. [5]. All 13 patients were recalled and fully re-evaluated prior to inclusion in the present study. A statistical analysis was made using the non-parametric Wilcoxon two sample test, in order to compare the initial and final BCVA between stage $2 \mathrm{a}$ and $2 \mathrm{~b}$ eyes. $\mathrm{P}$ values of $<0.05$ were considered statistically significant.

\section{RESULTS}

Of the 13 patients (14 eyes) reviewed, 9 were males (70\%) and 4 females (30\%). Eight of the 13 eyes were left and 6, right. One female had bilateral Coats' disease (7\%). The age of the 13 patients at diagnosis ranged from 5 to 33 (mean, $17.7 \pm 7.8$ ) years. At first examination, best corrected visual acuity (BCVA) ranged from 1.0 to light perception (LP) (Table 1). According to Shields' classification, four eyes presented telangiectasia plus exudation without foveal involvement (stage 2a), seven had telangiectasia plus exudation with foveal involvement (stage 2b), and three, total retinal detachment (stage 3b) (Table 2). Mean BCVA of stage 2 and stage 2 b eyes was 0.85 (range 0.8-1.0) and 0.14 (range 0.3-0.02), respectively. Stage 3 b eyes had light perception only (Table 1).

Table 1. Fourteen eyes (13 patients) with Coats' disease: demographics, stage, treatment, and BCVA at presentation and last examination.

\begin{tabular}{|c|c|c|c|c|c|c|c|}
\hline Pat. & Age & Gender & Eye & Initial stage / BCVA & Treatment & FU (years) & Final BCVA \\
\hline 1 & 29 & $\mathrm{M}$ & $\mathrm{L}$ & $2 \mathrm{a} / 1.0$ & Laser & 37 & 1.0 \\
\hline 2 & 16 & $\mathrm{~F}$ & $\mathrm{~L}$ & $2 \mathrm{a} / 0.8$ & Laser + cryo & 32 & 0.9 \\
\hline 3 & 33 & $\mathrm{M}$ & $\mathrm{L}$ & $2 \mathrm{a} / 0.8$ & Laser & 32 & 0.8 \\
\hline 4 & 18 & $\mathrm{M}$ & $\mathrm{L}$ & $2 \mathrm{a} / 0.8$ & Laser & 41 & 1.0 \\
\hline 5 & 5 & $\mathrm{M}$ & $\mathrm{R}$ & $2 \mathrm{~b} / 0.1$ & Laser + cryo & 17 & 0.3 \\
\hline 6 & 18 & $\mathrm{M}$ & $\mathrm{L}$ & $2 \mathrm{~b} / 0.06$ & Laser + cryo & 36 & 0.04 \\
\hline 7 & 8 & $\mathrm{~F}$ & $\mathrm{R}$ & $2 \mathrm{~b} / 0.04$ & Laser + cryo & 33 & 0.04 \\
\hline 8 & 19 & $\mathrm{M}$ & $\mathrm{R}$ & $2 \mathrm{~b} / 0.3$ & Laser & 32 & 0.4 \\
\hline 9 & 19 & $\mathrm{~F}$ & $\mathrm{~L}$ & $2 \mathrm{~b} / 0.02$ & Laser & 29 & 0.02 \\
\hline 10 & 21 & $\mathrm{M}$ & $\mathrm{L}$ & $2 \mathrm{~b} / 0.2$ & Laser + cryo & 31 & 0.1 \\
\hline 11 & 20 & $\mathrm{~F}$ & $\mathrm{R}$ & $2 \mathrm{~b} / 0.3$ & Laser + cryo & 37 & 0.02 \\
\hline 11 & 20 & $\mathrm{~F}$ & $\mathrm{~L}$ & $3 \mathrm{~b} / \mathrm{PL}$ & Enucleation & & \\
\hline 12 & 16 & $\mathrm{M}$ & $\mathrm{R}$ & $3 \mathrm{~b} / \mathrm{PL}$ & CB-cryo & 30 & NPL \\
\hline 13 & 8 & $\mathrm{M}$ & $\mathrm{R}$ & $3 \mathrm{~b} / \mathrm{PL}$ & None & 18 & NPL \\
\hline
\end{tabular}

Age in years, $\mathrm{BCVA}=$ best corrected visual acuity, $\mathrm{CB}=$ ciliary body, Cryo $=$ retinal cryotherapy, Laser $=$ retinal argon laser photocoagulation, $\mathrm{R}=$ right, $\mathrm{L}=$ left. Patient $\# 11$ had bilateral disease.

Among 11 stage $2 \mathrm{a}$ and $2 \mathrm{~b}$ eyes, telangiectasia and exudation were found at the posterior pole in nine $(81 \%)$, whereas the temporal, lower upper and nasal sectors were involved in eight (72\%), six (54\%), four (36\%) and one (9\%) of the eyes, respectively. Retinal vascular abnormalities affected two to four sectors of nine (81\%) eyes. Partial shallow exudative retinal detachment was observed in five (71\%) out of seven stage $2 b$ eyes, most frequently in the temporal and inferior sector. 
One to four sessions of retinal green argon laser photocoagulation or cryotherapy of telangiectatic vessels was performed in eleven stage $2 \mathrm{a}$ and $2 \mathrm{~b}$ eyes. One out of four stage $2 \mathrm{a}$ and five out of seven stage $2 \mathrm{~b}$ eyes received both retinal argon laser photocoagulation and cryotherapy (Table 1). In all 11 eyes, gradual resolution of the exudation and regression of the telangiectasia were observed within two to six months.

Recurrences were recorded in five (45\%) out of eleven eyes. A few months after repeat retinal laser photocoagulation, exudation was greatly reduced, and telangiectasia had regressed. Most of the patients were followed up regularly at our Department, and all were recalled. At the last evaluation, the average follow up period of patients (11 eyes) with stage $2 \mathrm{a}$ and $2 \mathrm{~b}$ disease, was $32.5 \pm 6.2$ (range,17- 41) years. Mean BCVA was 0.92 (range, $0.8-1.0$ ) and 0.13 (range, $0.02-0.4$ ) in four stage $2 \mathrm{a}$ and seven stage $2 \mathrm{~b}$ eyes, respectively (Tables 1 and 2 ). The difference found between these two sets of visual acuity both at initial and final examination was statistically significant $(\mathrm{p}<$ 0.01). All the 11 eyes had normal intraocular pressure, no exudative retinal detachment and no visually significant cataract or macular degeneration. Three initial stage $3 \mathrm{~b}$ eyes lost light perception; of two eyes that progressed to neovascular glaucoma (stage 4), one was enucleated, and the other presented advanced stage 5 disease (Tables 1 and 2 ).

\section{DISCUSSION}

The term "Coats' disease" refers to an idiopathic, generally unilateral condition characterized by telangiectatic and aneurysmal changes in the retinal vessels associated with leakage of large quantities of yellowish subretinal exudate, which can cause bullous retinal detachment. Sub-retinal lipid deposition can lead to fibrovascular tissue formation, resulting in disciform scars in the macular region, as peripheral exudative lesions also tend to track lipids towards the macula [8]. Complications from long-standing retinal detachment are cataract formation and iridocyclitis. Some patients progress directly, and relatively painlessly, to phthisis, whereas others develop rubeosis iridis and neovascular glaucoma, and painful blind eye requiring enucleation.

The course of Coats' disease, which is difficult to predict, depends mainly on age at onset. None of the younger patients in our series presented with leukocoria and/or strabismus, both of which are considered signs of aggressive disease with an extremely poor anatomical and functional prognosis [1,2]. Coats' disease mainly affects subjects in the first and second decades of life. Our data regarding age at onset, gender and bilaterality are similar to those reported in large series $[1,2,6]$, but a delay in the diagnosis of our older patients with mild symptoms cannot be ruled out. We did not encounter patients with adult-onset disease ( $>35$ years), which is less frequent and typically less severe; in these patients visual loss occurs secondary to leakage of perifoveal telangiectasia causing macular edema and lipid deposition, but exudative retinal detachment is rare [9].

The choice of treatment for patients with Coats' disease depends on whether the condition is mild (stage 2a and 2b) or severe (stages 3 and 4). The most widely used regimens in the former condition are retinal ablative procedures such as argon or diode laser photocoagulation and cryotherapy [10,11]. Selective photocoagulation of the telangiectasia using a yellow-dye laser can also lead to resolution of exudative detachment, but poor visual outcome in 32 eyes with macular involvement [12], as recorded in our stage $2 b$ eyes. Interestingly, in our series, all the eyes without initial foveal involvement (stage 2a) presented slight improvement or maintained good VA throughout the follow-up period. It should be noted that the statistically significant difference in the initial and final BCVA between our stage $2 \mathrm{a}$ and $2 \mathrm{~b}$ groups is biased by the small sample size.

Table 2. Fourteen eyes with Coats' disease: initial staging according to Shields' classification and functional outcome.

\begin{tabular}{|ll|c|c|}
\hline & Initial stage & No. of eyes & Mean initial - final BCVA \\
\hline $1 \quad$ Retinal telangiectasia & 0 & \\
\hline $2 \mathrm{a} \quad \mathrm{RT}+$ extrafoveal exudation & 4 & $0.85-0.92$ \\
\hline $2 \mathrm{~b} \quad \mathrm{RT}+$ foveal exudation & & $0.15-0.13$ \\
\hline $3 \mathrm{a} \quad$ Subtotal exudative RD & 3 & \\
\hline $3 \mathrm{~b} \quad$ Total exudative RD & & $\mathrm{PL}-\mathrm{NPL}$ \\
\hline $4 \quad$ RD + secondary glaucoma & & \\
\hline $5 \quad$ Advanced end-stage & & \\
\hline
\end{tabular}

$\mathrm{BCVA}=$ best corrected visual acuity, $\mathrm{RT}=$ retinal telangiectasia, $\mathrm{RD}=$ retinal detachment

Ablation therapy is more effective if retinal telangiectasia is not extensive and the retina is only partially detached. At least annual surveillance of patients with Coats' disease is recommended for the early identification and treatment of recurrences, which occurred in five $(45 \%)$ of our stage 2 eyes. 
In eyes with bullous retinal detachment, for which cryotherapy and laser are ineffective, surgical reattachment, including pars plana vitrectomy procedures, may be attempted [13]. However no eye in our series required surgical repair for total retinal detachment or intravitreal injection of triamcinolone, which may be especially beneficial in eyes with total bullous exudative detachment [14].

Intravitreal bevacizumab combined with thermal ablation has yielded encouraging results as adjuvant therapy, especially in the advanced stages of Coats' disease [15]. Resolution of the subretinal fluid and exudation, and regression of the telangiectasia were recently reported in both pediatric and adult patients following initial treatment with intravitreal injection of bevacizumab [16]. But the intravitreal injection of bevacizumab carries a 50\% risk of the development of vitreoretinal fibrosis and potential traction retinal detachment [17], although it should be borne in mind that vitreoretinal fibrosis can occur in the natural course of Coats' disease. However, as the increasing severity of Coats' disease is significantly associated with intraocular vascular endothelial growth factor (VEGF) concentrations [18], the intravitreal injection of anti-VEGF drugs appears a rational therapeutic option that may enrich the therapeutic armamentarium in the treatment of Coats' disease; this approach therefore merits further clinical research [19]. Unfortunately no therapy was available when George Coats first described the disease in 1908 [20].

\section{CONCLUSION}

Our experience highlights that appropriate diagnosis and therapy are mandatory in the management of Coats' disease, a rare idiopathic progressive disorder that usually affects young males. In our small series of patients with an exceptionally long (mean, 32 years) follow-up, the best visual outcomes were obtained in eyes without initial foveal involvement (stage 2a), which maintained their improved mean BCVA from 0.85 to 0.92 Snellen lines. The poor mean initial BCVA $(0.15)$ of stage $2 b$ eyes minimally deteriorated $(0.13)$ over time, but none of these eyes progressed to advanced stages of the disease.

In our experience, laser photocoagulation and/or cryotherapy of peripheral retinal telangiectasia and exudation are of crucial importance in reducing the risk of sight-threatening progression toward the posterior pole and retinal exudative detachment. A lifelong follow-up is required in order to identify and treat newly affected retinal areas with ablation therapy, to prevent further retinal damage.

\section{CONFLICT OF INTEREST}

The authors confirm that this article content has no conflict of interest.

\section{ACKNOWLEDGEMENTS}

The authors are grateful to Dr Fabiano Cavarzeran for his statistical support.

\section{REFERENCES}

[1] Shields JA, Shields CL, Honavar SG, Demirci H. Clinical variations and complications of Coats disease in 150 cases: the 2000 Sanford Gifford Memorial Lecture. Am J Ophthalmol 2001; 131(5): 561-71. [http://dx.doi.org/10.1016/S0002-9394(00)00883-7] [PMID: 11336930]

[2] Spitznas M, Joussen F, Wessing A, Meyer-Schwickerath G. Coat's disease. An epidemiologic and Fluorescein angiographic study. Albrecht Von Graefes Arch Klin Exp Ophthalmol 1975; 195(4): 241-50. [http://dx.doi.org/10.1007/BF00414937] [PMID: 1080374]

[3] Silodor SW, Augsburger JJ, Shields JA, Tasman W. Natural history and management of advanced Coats' disease. Ophthalmic Surg 1988; 19(2): 89-93. [PMID: 3347463]

[4] Char DH. Coats' syndrome: long term follow up. Br J Ophthalmol 2000; 84(1): 37-9. [http://dx.doi.org/10.1136/bjo.84.1.37] [PMID: 10611097]

[5] Shields JA, Shields CL, Honavar SG, Demirci H, Cater J. Classification and management of Coats disease: the 2000 Proctor Lecture. Am J Ophthalmol 2001; 131(5): 572-83. [http://dx.doi.org/10.1016/S0002-9394(01)00896-0] [PMID: 11336931]

[6] Morris B, Foot B, Mulvihill A. A population-based study of Coats disease in the United Kingdom I: epidemiology and clinical features at diagnosis. Eye (Lond) 2010; 24(12): 1797-801. [http://dx.doi.org/10.1038/eye.2010.126] [PMID: 20865031]

[7] Rishi P, Rishi E, Uparkar M, et al. Coats' disease: an Indian perspective. Indian J Ophthalmol 2010; 58(2): $119-24$. [http://dx.doi.org/10.4103/0301-4738.60081] [PMID: 20195034] 
[8] Adam RS, Kertes PJ, Lam WC. Observations on the management of Coats' disease: less is more. Br J Ophthalmol 2007; 91(3): 303-6. [http://dx.doi.org/10.1136/bjo.2006.103382] [PMID: 17020897]

[9] Smithen LM, Brown GC, Brucker AJ, Yannuzzi LA, Klais CM, Spaide RF. Coats' disease diagnosed in adulthood. Ophthalmology 2005; 112(6): 1072-8.

[http://dx.doi.org/10.1016/j.ophtha.2004.12.038] [PMID: 15882905]

[10] Schefler AC, Berrocal AM, Murray TG. Advanced Coats' disease. Management with repetitive aggressive laser ablation therapy. Retina 2008; 28(3): S38-41. [http://dx.doi.org/10.1097/IAE.0b013e318163cd7c] [PMID: 18317343]

[11] Budning AS, Heon E, Gallie BL. Visual prognosis of Coats' disease. J AAPOS 1998; 2(6): 356-9. [http://dx.doi.org/10.1016/S1091-8531(98)90034-9] [PMID: 10532724]

[12] Nucci P, Bandello F, Serafino M, Wilson ME. Selective photocoagulation in Coats' disease: ten-year follow-up. Eur J Ophthalmol 2002; 12(6): 501-5. [PMID: 12510719]

[13] Mrejen S, Metge F, Denion E, Dureau P, Edelson C, Caputo G. Management of retinal detachment in Coats disease. Study of 15 cases. Retina 2008; 28(3): S26-32.

[http://dx.doi.org/10.1097/IAE.0b013e31816b3158] [PMID: 18317340]

[14] Othman IS, Moussa M, Bouhaimed M. Management of lipid exudates in Coats disease by adjuvant intravitreal triamcinolone: effects and complications. Br J Ophthalmol 2010; 94(5): 606-10 [http://dx.doi.org/10.1136/bjo.2009.168013] [PMID: 19955197]

[15] Ray R, Barañano DE, Hubbard GB. Treatment of Coats' disease with intravitreal bevacizumab. Br J Ophthalmol 2013; $97(3)$ : $272-7$. [http://dx.doi.org/10.1136/bjophthalmol-2012-302250] [PMID: 23269680]

[16] Zheng XX, Jiang YR. The effect of intravitreal bevacizumab injection as the initial treatment for Coats' disease. Graefes Arch Clin Exp Ophthalmol 2014; 252(1): 35-42. [http://dx.doi.org/10.1007/s00417-013-2409-1] [PMID: 23873253]

[17] Ramasubramanian A, Shields CL. Bevacizumab for Coats' disease with exudative retinal detachment and risk of vitreoretinal traction. Br J Ophthalmol 2012; 96(3): 356-9.

[http://dx.doi.org/10.1136/bjophthalmol-2011-300141] [PMID: 21653215]

[18] Zhao Q, Peng XY, Chen FH, et al. Vascular endothelial growth factor in Coats' disease. Acta Ophthalmol 2014; 92(3): e225-8. [http://dx.doi.org/10.1111/aos.12158] [PMID: 23764089]

[19] Sigler EJ, Randolph JC, Calzada JI, Wilson MW, Haik BG. Current management of Coats disease. Surv Ophthalmol 2014; 59(1): 30-46. [http://dx.doi.org/10.1016/j.survophthal.2013.03.007] [PMID: 24138893]

[20] Coats G. Forms of retinal disease with massive exudation. R Lond Ophthalmol Hosp Rep 1908; 17: 440-525.

Received: October 20, $2015 \quad$ Revised: November 30, $2015 \quad$ Accepted: November 30, 2015

(C) Perrone et al.; Licensee Bentham Open.

This is an open access article licensed under the terms of the Creative Commons Attribution-Non-Commercial 4.0 International Public License (CC BY-NC 4.0) (https://creativecommons.org/licenses/by-nc/4.0/legalcode), which permits unrestricted, non-commercial use, distribution and reproduction in any medium, provided the work is properly cited. 